\title{
Assessment of Major Burn Patients with Biochemical Markers
}

\author{
Cınar MA ${ }^{1 *}$, Erkılıc A ${ }^{2}$, Bayramlar $K^{1}$, Gunes $A^{2}$ and Yakut $Y^{1}$
}

${ }^{1}$ Faculty of Health Sciencies, Physical Therapy and Rehabilitation Department, Hasan Kalyoncu University, Turkey

${ }^{2} 25$ Aralık State Hospital, Burn Center, Turkey

\begin{abstract}
Burn injury causes serious mortality and morbidity. Especially all pathophysiologic responses are seen in burn patients who are affected in more than $20 \%$ of total body surface.

In the literature, biochemical studies on burns are usually studies investigating the effects of inflammation, sepsis and inhalation. However, studies that evaluated the wound healing and clinical course with biochemical parameters are limited. In particular, there were no studies investigating the effects of early physiotherapy on burn patients.

Using biochemical parameters to evaluate these physiological changes seen in major burns can give more objective data. Therefore, the aim of this review is to discuss the recent advances in research into the utility of biomarkers in burn injury and to examine the effect of physiotherapy on these parameters.
\end{abstract}

Keywords: Major burns; Prealbumin; Fibronectin; Transferrin; Physiotherapy

\section{Introduction}

In skin and organic tissues; injuries caused by many factors such as chemical, electrical, friction, flame, and radioactivity are called burns [1]. Burn injury causes serious mortality and morbidity. In addition, hospitalization period and rehabilitation period is one of the longest traumas [2].

Lipolysis, proteolysis, glycolysis and high fever and hyperdynamic and hypermetabolic responses are seen in burn patients who are affected in more than $20 \%$ of total body surface area. These hypermetabolic responses in patients lead to a decrease in lean muscle mass, delay in wound healing, weakening of the immune system and serious mortality [3]. In the first 24 hours after the major burns, fluid accumulation is seen in the interstitial space due to increased vascular permeability. The reduced intravascular volume affects tissue perfusion if not interfered Cardiac output decreases, all systems including the gastrointestinal system and renal system are affected. Depending on the burn, the electrolytes in the body are also affected and as a result of this effect cell death may occur [4].

For an optimal treatment after burn, all pathophysiological changes that may occur locally and systemically after injury should be known well. A good evaluation of burn injury is also required for a good treatment. The area affected by the burn should be evaluated in depth and the clinical process should be shaped accordingly [5].

The role of physiotherapy in the treatment of burns with surgery and medical treatment is becoming increasingly important. In particular, major burn patients need a long period of physiotherapy and rehabilitation, including the acute phase and the post-discharge period [6].

There are several studies in the literature evaluating the effects of inflammation and inhalation burns in burn patients with biochemical parameters. However, studies that evaluated the wound healing and clinical course with biochemical parameters are limited. In particular there were no studies investigating the effects of early physiotherapy on burn patients.

Using biochemical parameters to evaluate these physiological changes seen in major burns can give more objective data. Therefore, the aim of this review is to discuss the recent advances in research into the utility of biomarkers in burn injury and to examine the effect of physiotherapy on these parameters.

\section{Which Biochemical Markers can be Evaluated in the follow-up of Burn Injury?}

Biochemical parameters; It can be defined as markers that can be measured and evaluated as an objective indicator of normal biological processes, pathogenic processes, or responses to a treatment. The World Health Organization (WHO) has defined each measure as a biochemical parameter, which allows for the comparison of a potential biological system with any potential hazard [7].

An ideal biomarker should be obtained easily and quickly. It must be precise, specific and repeatable. These markers should help us to understand the pathophysiology of diseases, identifying early and accurate diagnoses of certain complications and determine the severity of the disease [7].

There is no sharp definition of biochemical markers used in burn injury. The markers are determined according to the ascertained prognostic purpose and evaluated pathophysiological changes, according to the patient [7]

\section{Historical Development of Biochemical Markers related to Burn Injury}

İnevaluated the biochemical marker of interleukin-1 receptor antagonist (IL-1RA) in burn patients [8]. They observed that this parameter increased especially in inhalation burns. In another study by Vindenes in 1998, plasma cytokine levels were evaluated in burn patients. In particular, patients with more than a percentage of burns were reported to be more elevated [9]. Biochemical markers related to burn injury continued in 2000. Procalcitonin parameter could be used for the evaluation of sepsis in burn patients [10]. Biochemistry studies of burn patients have been continuing until today as shown in Table 1.

*Corresponding author: Cınar MA, Faculty of Health Sciencies, Physical Therapy and Rehabilitation Department, Hasan Kalyoncu University, Turkey, Tel: 03422118080 , E-mail: muratali.cinar@hku edu.tr

Received November 15, 2018; Accepted December 10, 2018; Published December 25, 2018

Citation: Cınar MA, Erkılıc A, Bayramlar K, Gunes A, Yakut Y (2019) Assessment of Major Burn Patients with Biochemical Markers. Mol Biol 8: 226. doi: 10.4172/21689547.1000226

Copyright: ( 2019 Cınar MA, et al. This is an open-access article distributed under the terms of the Creative Commons Attribution License, which permits unrestricted use, distribution, and reproduction in any medium, provided the original author and source are credited. 


\begin{tabular}{|c|c|c|}
\hline Year & Biochemical marker & Reference \\
\hline 1995 & IL1Ra & Mandrup-Polsen et al. [8] \\
\hline 1996 & IL1Ra & Endo et al. [11] \\
\hline 1997 & TNFa & Yeh et al. [12] \\
\hline 1998 & IL1Ra, IL1b & Vindenes et al [9] \\
\hline 1999 & IL6 & Yeh et al. [13] \\
\hline 2000 & IL10 & Yeh et al. [14] \\
\hline 2002 & TGFb1 & Yeh et al. [15] \\
\hline 2008 & G-CSF, MCP-1, IL6, IL8 & Jeschke et al. [16] \\
\hline 2010 & $\begin{array}{c}\text { IL6, IL8, IL10 } \\
\text { IL6, Leukocyte surface markers }\end{array}$ & $\begin{array}{l}\text { Csontos et al. [17] } \\
\text { Voldi et al. [18] }\end{array}$ \\
\hline 2011 & $\begin{array}{c}\text { IL10 } \\
\text { Procalcitonin }\end{array}$ & $\begin{array}{l}\text { Inatsu et al. [19] } \\
\text { Mann et al. [20] }\end{array}$ \\
\hline 2012 & $\begin{array}{l}\text { IL8 } \\
\text { IL1Ra, IL1b, IL8, IL10, IL12p70, C5a } \\
\text { IL1b, Receptor of TNF a } \\
\text { Procalcitonin }\end{array}$ & $\begin{array}{c}\text { Albright et al. [21] } \\
\text { Davis et al. [22] } \\
\text { Salgado et al. [23] } \\
\text { Lavrentieva et al. [24] }\end{array}$ \\
\hline 2013 & $\begin{array}{c}\text { IL1Ra } \\
\text { IL10, IL12p70 } \\
\text { K6, MMP9, CD44 } \\
\text { IL33 }\end{array}$ & $\begin{array}{c}\text { Davis et al. [25] } \\
\text { Jones et al. [26] } \\
\text { Simonetti et al. [27] } \\
\text { Yin et al. [28] }\end{array}$ \\
\hline 2014 & $\begin{array}{c}\text { IL6, IL8, TGFb1, MCP-1, CRP } \\
\text { IL6, IL8, G-CSF, MCP-1, MIP-1b, CRP } \\
\text { Leucocyte surface markers, } \\
\text { N-terminal pro-B-type natriuretic peptide } \\
\text { Cystatin C, NGAL }\end{array}$ & $\begin{array}{l}\text { Kraft et al. [29] } \\
\text { Jeschke et al. [30] } \\
\text { Szelig et al. [31] } \\
\text { Paratz et al. [32] } \\
\text { Yang et al. [33] }\end{array}$ \\
\hline 2015 & $\begin{array}{c}\text { IL8 } \\
\text { IL6, IL8, TNFa }\end{array}$ & $\begin{array}{l}\text { Yeh et al. [34] } \\
\text { Reper et al. [35] }\end{array}$ \\
\hline
\end{tabular}

Table 1: Historical development of biochemical markers related to burn injury.

\section{Clinical Experience}

When we look at the historical development of biochemical markers associated with burn; these parameters are more commonly used to assess the effects of inflammation. It may not be enough to assess the effects of physiotherapy.

In the recent studies, Cinar used markers such as fibronectin, prealbumin, procalcitonin, transferrin, CRP, glucose, insülin to evaluate the effectiveness of physiotherapy.

\section{Prealbumin (Transthyretin)}

Prealbumin first described as Transthyretin (TTR) in 1942, was named as Thyroxine-Binding Prealbumin (TBPA) or prealbumin due to electrophoretic migration just before albumin. However, both definitions are used in the literature [36]. However, both definitions are used in the literature. Prealbumin is a non-glycosylated protein that forms a complex molecule with Retinol Binding Protein (RBP). It allows the transport of complex retinol and T4 thyroid hormone. Prealbumin is both synthesized and catabolized by the liver, excreted by the kidney and gastrointestinal tract. Prealbumin is both synthesized and catabolized by the liver, excreted by the kidney and gastrointestinal tract. The half-life is approximately 1.9 days. The short half-life of prealbumin and its richness in tryptophan make it a nutritionally sensitive marker [36]. The reference range is 0.20 to $0.40 \mathrm{~g} / \mathrm{L}$, but age and gender can be important to interpret a test. The prealbumin levels in women may be slightly lower than in men because prealbumin synthesis is controlled by sex steroid hormones [36].

The serum concentration of prealbumin may be affected by many factors, including new dietary intake. In cases of severe renal failure, the use of corticosteroids, non-steroidal anti-inflammatory agents and oral contraceptives may increase the prealbumin value. Liver disease decreases in dialysis, hyperthyroidism and marked hyperglycemia, but the most common cause of inflammation is acute inflammation.
This response is mediated by pro-inflammatory cytokines (IL-6, IL-1, $\mathrm{TNF} \alpha$ ) [36].

Prealbumin was first used as a marker of Protein-Energy Malnutrition (PEM) in the 1970s. In recent years, Fat-Free Mass (FFM) and Fat Mass (FM) calculations are made by bioelectrical impedance method to define malnutrition. However, despite recent research, the most sensitive biochemical parameter for lean muscle mass, amino acid synthesis and energy malnutrition is prealbum [36].

\section{Fibronectin}

Fibronectin is a kind of glycoprotein found in all kinds of tissues and has an important role in the interaction of many different cell matrices. Fibronectin is one of the building blocks of extracellular matrix formation [37]. All fibronectin molecules consist of the same basic functional areas. Although encoded by single genes, it is subdivided into approximately 50 exon sequences in an RNA sequence. The fibronectin gene consists of three general types of homologous repeating units or modules called Type I, II and III. In this gene, each repeating module of type I or II homology unit is encoded by a separate exon. However, the type-II gene is formed by the contribution of the other gene. Type I modules are used to connect fibrin, heparin or collagen. Type II modules are only found in the collagen binding domain and type III modules are used in the domain that binds to cells. Due to specific functional areas and binding sites, fibronectin interacts with different cell types, cytokines, and extracellular matrix (ECM) [37]

Fibronectin is required for both tissue formation and wound repair and connective tissue repair. Fibronectin interacts with other cells to form an ECM at each stage of wound healing, but at the same time, the role of fibronectin in the early stage of wound healing is more important, where it is bound to thrombocytes and fibrin. The fibronectin marker is also used to monitor wound healing in the clinic. A low-progression indicates a delay in wound healing, whereas a higher than normal gives clues about an adhesion or scar formation [37,38].

\section{The transferrin receptor (TfR)}

\section{Transferrin receptor}

Transferrin receptor is the iron source of various organ cellular components [39]. The level of serum ferritin is a useful indicator for the condition of the iron reservoir. When iron stores are depleted, serum ferritin is below $12-15 \mu \mathrm{g} / \mathrm{L}$, but this is not an indicator of inflammation alone. In view of these mutations of TfR and ferritin, the ratio of $\mathrm{TfR} /$ ferritin is a valuable measure of the degree of iron deficiency. In a phlebotomy study in which iron status and iron deficiency were calculated, the rate of serum TfR/ferritin reflected body iron status and iron deficiency. In other words, positive values indicate that iron is stored and negative values indicate iron deficiency [39].

\section{CRP (C-Reactive protein)}

CRP is often used as a biomarker for an acute inflammatory condition. CRP values indicate the presence and severity of inflammation [40].

\section{Procalcitonin (PCT)}

Procalcitonin is a biochemical parameter that positively correlates with sepsis and mortality rates. In the last decade, PCT has become increasingly popular as a new infection marker in the ICU. It has been emphasized in several studies that it is a valuable marker that identifies the seriousness of the guiding treatment of the underlying disease [41]. 


\begin{tabular}{|l|c|}
\hline \multicolumn{1}{|c|}{ Parameters of Physiotherapy (PT) Protocol } & Early Stage Burn Physiotherapy Protocol \\
\hline Duration of PT & $45-60$ min \\
\hline Times per day & 1 \\
\hline How many times a week & 4 \\
\hline PT on admission & From the first day \\
\hline PT after grafting & Respiratory exercises according to the state of affection \\
\hline Pulmonary physiotherapy & Active and passive Range-of-Motion (ROM) exercises according to the patient's condition \\
\hline Exercise therapy & From the first day \\
\hline Training Of mobilization and ambulation & From the first day \\
\hline Appropriate anti-contracture positioning & \\
\hline
\end{tabular}

Table 2: Properties of ESBPP.

\section{Early stage burn physiotherapy protocol (ESBPP)}

ESBPP patients who were previously exposed to burn trauma were taken to a physiotherapy program after an immobilization period of 7 to 10 days. But in the last 10 years, this understanding has been replaced by the idea that it is necessary to start the physiotherapy program in the early period. In particular, if the hypermetabolic response begins within the first 48 hours, the patient should start the physiotherapy program as early as possible from the time of admission. For this reason, we applied Early Stage Burn Physiotherapy Protocol (ESBPP) to our patients aws shown in Table 2 [42].

In patients with major burns; delayed wound healing, impaired protein metabolism, and the emergence of the inflammatory process adversely affect the clinical course of the disease. Parameters such as fibronectin, prealbumin and transferrin also provide important information in the follow-up of these processes. Çınar stated in their study that decreasing fibronectin values in the acute period have increased to the normal reference range in patients with major burns physiotherapy [42].

In another study he reported that physiotherapy reduced the level of increased glucose and triglycerides due to hypermetabolic response in burn patients [43].

In the study, Çınar Investigated the effect of physiotherapy on biochemical parameters in patients with major burns and concluded that early physiotherapy (ESBPP) positively affects parameters such as fibronectin, prealbumin and transferrin [44]. They also stated that the positive effect of fibronectin and the prealbumin values that inform the patient about the muscle metabolism and clinical course of the wound healing process in the acute phase will bring a different perspective to the literature and add power to it [44].

Çınar stated that physiotherapy is effective on glucose, insulin, prealbumin and procalcitonin levels in both types of burns. In the study that named "The Effect of Physiotherapy on Glucose, Insulin, Prealbumin and Procalcitonin in two Different Burn injuries: Pilot Study" [45].

\section{Conclusion}

The occurrence of inflammation is inevitable after burn injuries. In particular, it has been reported in the literature that major postburn inflammatory mediators have increased. In addition, the effects of inhalation burns and sepsis were evaluated in burn patients. Consequently, some biomarkers have been described as potential therapeutic targets [7]. However, these markers may not be sufficient for the follow-up of burn patients. In particular, the use of fibronectin biomarker to monitor wound healing may guide the evaluation of professionals working in this area [42].
In recent years, prealbumin has been used to monitor the clinical course of the patient rather than the nutritional marker in patients who have undergone major trauma. Especially in burn patients, prealbumin levels are thought to be directly effective on the clinical course of the disease and patient mortality [46]. Therefore, we believe that the use of prealbumin biomarker may be important in the evaluation of burn injury.

Iron deposition is reduced due to inflammation and impaired liver function in major burn patients and therefore the transferrin value is adversely affected. We believe that in addition to other parameters, transferrin should be evaluated especially in the follow-up of elderly patients.

Treatment of burn patients requires a very serious multidisciplinary approach. The treatment program of the patient does not include a single understanding; many parameters such as medical treatment, surgical treatment, nutrition, and physiotherapy should be included in the treatment program. Surgical treatment has a great place among these parameters. The patient undergoes multiple surgical procedures until he is discharged from hospital admission and these operations prolong the immobilization period of the patient. The prolonged immobilization time affects the clinical course of the patient negatively.

Physiotherapy of burn patients has many parameters. It is not considered that any parameter gives direct superiority to another parameter. However, we concluded that the mobilization of patients in the earliest possible period is a very important parameter. Especially, considering that surgical treatments affect patient mobilization, mobilization training should be given priority in the physiotherapy program.

ESBPP must be presented in the treatment programs of major burn patients. In order to follow the clinical course of the patients; parameters such as fibronectin, prealbumin, transferrin, procalcitonin should also be taken into consideration.

Therefore, searches that related to burn injuries, especially major burns, should focus on preventing complications, wound healing and designing new therapeutic targets such as physiotherapy and validating new experimental findings.

\section{References}

1. Masood RA, Wain ZN, Tariq R, Bashir I (2016) Burn cases, their management and complications: A review. Int J Curr Pharm Res 5(12): 103-105.

2. Brusselaers N, Monstrey S, Vogelaers D, Hoste E, Blot S (2010) Severe burn injury in Europe: A systematic review of the incidence, etiology, morbidity, and mortality. Crit care 14(5): R188. 
3. Mandell SP, Gibran NS (2014) Early enteral nutrition for burn injury. Adv wound care 3(1): 64-70.

4. Gillenwater J, Garner W (2017) Acute fluid management of large burns: Pathophysiology, monitoring, and resuscitation. Clin Plast Surg 44(3):4 35-694.

5. Atiyeh BS, Gunn SW, Hayek SN (2005) State of the art in burn treatment. World J Plast Surg 29(2): 131-148.

6. Schneider JC, Qu HD, Lowry J, Walker J, Vitale E, et al. (2012) Efficacy of inpatient burn rehabilitation: A prospective pilot study examining range of motion, hand function and balance. Burns 38(2): 164-171.

7. Ruiz-Castilla M, Roca O, Masclans JR, Barret JP (2016) Recent advances in biomarkers in severe burns. Shock 45(2): 117-125.

8. Mandrup-Poulsen T, Wogensen LD, Jensen M, Svensson P, Nilsson $P$ (1995) Circulating interleukin-1 receptor antagonist concentrations are increased in adult patients with thermal injury. Crit Care Med 23(1): 26-33.

9. Vindenes HA, Ulvestad E, Bjerknes R (1998) Concentrations of cytokines in plasma of patients with large burns: their relation to time after injury, burn size, inflammatory variables, infection, and outcome. Eur J Surg 164(9): 647-656.

10. Mann EA, Wood GL, Wade CE (2011) Use of procalcitonin for the detection of sepsis in the critically ill burn patient: a systematic review of the literature. Burns 37(4): 549-558.

11. Endo S, Inada K, Yamada Y, Kasai T, Takakuwa T, et al. (1996) Plasma levels of interleu- kin-1 receptor antagonist (IL-1RA) and severity of illness in patients with burns. J Med 27(1-2): 57-71.

12. Yeh FL, Lin WL, Shen HD, Fang RH (1997) Changes in serum tumour necrosis factor- alpha in burned patients. Burns 23(1): 6-10.

13. Yeh FL, Lin WL, Shen HD, Fang RH (1999) Changes in circulating levels of interleukin 6 in burned patients. Burns 25(2): 131-136.

14. Yeh FL, Lin WL, Shen HD (2000) Changes in circulating levels of an anti- inflammatory cytokine interleukin 10 in burned patients. Burns 26(5): 454-459.

15. Yeh FL, Shen HD, Fang RH (2002) Deficient transforming growth factor beta and interleukin-10 responses contribute to the septic death of burned patients. Burns 28(7): 631-637.

16. Jeschke MG, Chinkes DL, Finnerty CC, Kulp G, Suman OE (2008) Pathophysiologic response to severe burn injury. Ann Surg 248(3): 387-401.

17. Csontos C, Foldi V, Palinkas L, Bogar L, Roth E, et al. (2010) Time course of pro- and anti-inflammatory cytokine levels in patients with burns: prognostic value of interleukin-10. Burns 36(4): 483-494.

18. Foldi V, Lantos J, Bogar L, Roth E, Weber G, et al. (2010) Effects of fluid resuscitation methods on the pro and anti-inflammatory cytokines and expression of adhesion molecules after burn injury. $J$ Burn Care Res 31(3): 480-491.

19. Inatsu A, Kogiso M, Jeschke MG, Asai A, Kobayashi M, et al. (2011) Lack of Th17 cell generation in patients with severe burn injuries. J Immunol 187(5): 2155-2161.

20. Mann EA, Wood GL, Wade CE (201) Use of procalcitonin for the detection of sepsis in the critically ill burn patient: a systematic review of the literature. Burns 37(4): 549-558.

21. Albright JM, Davis CS, Bird MD, Ramirez L, Kim H (2012) The acute pulmonary inflammatory response to the graded severity of smoke inhalation injury. Crit Care Med 40(4): 1113-1121.

22. Davis CS, Albright JM, Carter SR, Ramirez L, Kim H, et al. (2012) Early pulmonary immune hypores- ponsiveness is associated with mortality after burn and smoke inhalation injury. J Burn Care Res 33(1): 26-35.

23. Salgado RM, Alca'ntara L, Mendoza-Rodr'ıguez CA, Cerbo'n M, Hidalgo- Gonza'lez C (2012) Post-burn hypertrophic scars are characterized by high levels of IL-1b mRNA and protein and TNF-a type I receptors. Burns 38(5): 668-676.

24. Lavrentieva A, Papadopoulou S, Kioumis J, Kaimakamis E, Bitzan M (2012) PCT as a diagnostic and prognostic tool in burn patients. Whether time course has a role in monitoring sepsis treatment. Burns 38(3): 356-363.

25. Davis CS, Janus SE, Mosier MJ, Carter SR, Gibbs JT, et al. (2013) Inhalation injury severity and systemic immune perturbations in burned adults. Ann Surg 257(6): 1137-1146.

26. Jones SW, Zhou H, Ortiz-Pujols SM, Maile R, Herbst M, et al. (2013) Bronchoscopy-derived correlates of lung injury following inhalational injuries: a prospective observational study. PLoS One 8(5): e64250.

27. Simonetti O, Lucarini G, Cirioni O, Zizzi A, Orlando F (2013) Delayed wound healing in aged skin rat models after thermal injury is associated with an increased MMP-9, K6 and CD44 expression. Burns 39(4): 776-787.

28. Yin H, Li X, Hu S, Liu T, Yuan B, et al. (2013) IL-33 accelerates cutaneous wound healing involved in upregulation of alternatively activated macrophages. Mol Immunol 56(4): 347-353.

29. Kraft R, Herndon DN, Finnerty CC, Shahrokhi S, Jeschke MG (2014) Occurrence of multiorgan dysfunction in pediatric burn patients: incidence and clinical out- come. Ann Surg 259(2): 381-387.

30. Jeschke MG, Gauglitz GG, Finnerty CC, Kraft R, Mlcak RP, et al. (2014) Survivors versus nonsurvivors postburn: differences in inflammatory and hyper- metabolic trajectories. Ann Surg 259(4): 814-823.

31. Szelig L, Rendeki S, Foldi V, Lantos J, Bogar L, et al. (2014) Time course of $C D$ marker expression in patients with burns and its prognostic value. Burns 40(4): 575-582.

32. Paratz JD, Lipman J, Boots RJ, Muller MJ, Paterson DL (2014) A new marker of sepsis post burn injury? Crit Care Med 42(9): 2029 -2036 .

33. Yang HT, Yim H, Cho YS, Kym D, Hur J (2014) Assessment of biochemical markers in the early post-burn period for predicting acute kidney injury and mortality in patients with major burn injury: Comparison of serum creatinine, serum cystatin-C, plasma and urine neutrophil gelatinase- associated lipoca. Crit Care 18(4): R151.

34. Yeh FL, Lin WL, Shen HD, Fang RH (1997) Changes in levels of serum IL-8 in burned patients. Burns 23(7-8): 555-559.

35. Reper P, Heijmans W (2015) High-frequency percussive ventilation and initial bio- marker levels of lung injury in patients with minor burns after smoke inhalation injury. Burns 41(1): 65-70.

36. Delliere S, Cynober L (2017) Is transthyretin a good marker of nutritional status? Clin Nutr 36(2): 364-370.

37. Lenselink EA (2015) Role of fibronectin in normal wound healing. Int Wound J 12(3): 313-316

38. Cohen C, Leal MF, Belangero PS, Figueiredo EA, Smith MC, et al. (2016) The roles of Tenascin $C$ and Fibronectin 1 in adhesive capsulitis: a pilot gene expression study. Clinics 71(6): 325-331.

39. Skikne BS (2008) Serum transferrin receptor. Am J Hematol 83(11): 872-875.

40. Luzzani A, Polati, E, Dorizzi R, Rungatscher A, Pavan R, et al (2003) Comparison of procalcitonin and C-reactive protein as markers of sepsis. Crit Care Med 31(6): 1737-1741. 
41. Vincent JL, Van Nuffelen M, Lelubre C (2015) Host response biomarkers in sepsis: The role of procalcitonin. Sepsis: Diagnostic Methods and Protocols 1237: 213- 224.

42. Cınar M (2017) Effect of early physiotherapy on fibronectin level in major burn patients: A pilot study. J Exerc Rehabil 4(3): 105110.

43. Çınar M, Erkılıç A, Güneş A, Bayramlar K, Yakut Y (2017) The effect of early physiotherapy on metabolic syndrome in patients with major burns: Pilot Study. $6^{\text {th }}$ National Physiotherapy Congress, Oral Presentation.
44. Çınar M, Erkılıç A, Güneş A, Bayramlar K, Yakut Y (2017) The effect of early physiotherapy on biochemical parameters in major burn patients. $12^{\text {th }}$ National Wound Congress, Antalya, Oral Presentation.

45. Çınar M, Erkılıç A, Bayramlar K, Kocamaz D, Güneş A (2018) The effect of physiotherapy on glucose, Insulin, prealbumin and procalcitonin in two different burn injuries: Pilot study. $3^{\text {th }}$ International Health Congress, Ankara, Oral Presentation.

46. Yang HT, Yim H, Cho YS, Kim D, Hur J, et al. (2014) Serum transthyretin level is associated with clinical severity rather than nutrition status in massively burned patients. JPEN 38(8): 966-972. 